\title{
The androgen receptor mediates antiapoptotic function in myometrial cells
}

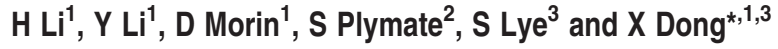

During pregnancy, myometrial phenotype is programmed into three characteristic stages referred to as the early proliferative, the midterm hypertrophic, and the late contractile stage. Increased myometrial growth in the early and midterm of pregnancy involves a complex process of cell proliferation, antiapoptosis and differentiation. We have previously demonstrated that the androgen receptor (AR) is required for myometrial cell proliferation by modulating IGF-1 signaling during early pregnancy. Here, we report that $A R$ also exerts its antiapoptotic function in human myometrial cells. Enhanced AR expression protects, whereas AR silencing sensitizes myometrial cells to both intrinsic and extrinsic apoptotic stimuli. AR agonist inhibits, whereas AR antagonist induces myometrial cells to undergo apoptotic cell death. Gene microarray analysis confirms that the central functions of AR in myometrial cells are to regulate cell cycling and apoptosis through three major gene groups involving the epidermal growth factor (EGF) signaling, RNA splicing and DNA repair processes. AR mediates its antiapoptotic function through two distinct pathways. In the receptor-dependent pathway, AR is required for the expression of several protein factors within the EGF signaling pathway. Through the PI3K/Akt pathway, AR enhances the expression of the antiapoptotic protein Mcl-1. In the ligand-dependent pathway, AR agonist triggers the activation of Src kinase, which in turn phosphorylates STAT3 to increase Mcl-1 expression. We conclude from these results that the AR signaling exerts antiapoptotic function in myometrial cells, further supporting its key role in programming of myometrial phenotype.

Cell Death and Disease (2014) 5, e1338; doi:10.1038/cddis.2014.303; published online 17 July 2014

The myometrium demonstrates remarkable plasticity during pregnancy, manifest by changes in myometrial phenotype across pregnancy starting from the early proliferative, to the midterm synthetic and the later contractile stages. ${ }^{1,2}$ It concludes with postpartum uterine remodeling to complete the reproductive cycle following labor and returns to its nonpregnant receptive state. The proliferative stage of pregnancy involves a complex process of cell proliferation, apoptosis as well as differentiation. At this stage, the myometrial phenotype is characterized by an enhanced proliferation index for example, PCNA and BrdU incorporation. ${ }^{3}$ In addition, emerging evidence suggests that antiapoptotic mechanisms are also developed to cooperate with myometrial growth. Using a pregnant rat model, we showed high levels of the antiapoptotic proteins, Bcl2 and Bcl2L1, expressed throughout the proliferative stage. ${ }^{3}$ In addition, although there are several executioner caspases (e.g. caspase 3, 6 and 7) activated during this stage, apoptotic cell death is not observed in myometrial cells. ${ }^{3-5}$ As the early proliferative phase of pregnancy is essential to accumulate enough myometrial cell numbers and contractile capacity to engage in parturition, these observations suggest that antiapoptotic mechanisms must be coordinately developed along with cell proliferation during early pregnancy to achieve optimal myometrial growth. Thus, investigation of the antiapoptotic mechanisms of myometrial cells will contribute significantly to our understanding the physiology of uterus and the clinical management of pregnancy and labor progression.

Signaling mediated by estrogen and progesterone receptors had been demonstrated to be important for myometrial growth. ${ }^{6-9}$ As transcriptional factors, these steroid receptors regulate expression of several growth factors to modulate myometrial cell growth. ${ }^{10-12}$ Growth factors such as insulinlike growth factor (IGF) and epidermal growth factor (EGF) bind their cognate tyrosine kinase receptors and trigger multiple downstream signaling cascades such as PI3K/Akt and Ras-Erk/MAPK. ${ }^{13,14}$ Steroid receptors can also exert non-genomic actions to control cell proliferation. Ligandactivated receptors can recruit Src kinase and activate its downstream signaling cascade. ${ }^{15,16}$ Therefore, the mutual interplay between steroid receptors and growth factors are vital for myometrial growth.

The androgen receptor (AR), a nuclear steroid receptor, is also expressed in the myometrium. Serum androgen levels

\footnotetext{
${ }^{1}$ The Vancouver Prostate Centre, Department of Urologic Sciences, University of British Columbia, Vancouver, British Columbia, Canada; ${ }^{2}$ Department of Medicine, University of Washington School of Medicine and VAPSHCS-GRECC, Seattle, Washington, USA and ${ }^{3}$ Department of Obstetrics and Gynaecology, University of Toronto, Toronto, Ontario, Canada

*Corresponding author: X Dong, The Vancouver Prostate Centre, Department of Urologic Sciences, University of British Columbia, 2660 Oak Street, Vancouver, British Columbia, Canada V6H 3Z6. Tel: +1 250604875 4111, ext 63020; Fax: +1 250604875 5654; E-mail: xdong @ prostatecentre.com

Abbreviations: AR, androgen receptor; EGF, epidermal growth factor; PI3K, Phosphatidylinositol-4,5-bisphosphate 3-kinase; Akt, protein kinase B; Mcl-1, induced myeloid leukemia cell differentiation protein; Src, proto-oncogene tyrosine-protein kinase; STAT3/5, signal transducer and activator of transcription 3/5; Bcl2, B-cell lymphoma 2; Bcl-xL, B-cell lymphoma-extra-large; PARP1, poly [ADP-ribose] polymerase 1; CASP3, caspase 3; FACS, fluorescence-activated cell sorting; CPT, camptothecin; SHC, Src homology 2 domain containing transforming protein; PKC, protein kinase C; Grb2, growth factor receptor-bound protein 2; RASA, Ras GTPaseactivating protein

Received 17.3.14; revised 06.6.14; accepted 11.6.14; Edited by A Stephanou
} 
start to increase progressively during the pregnant luteal phase, initiated by the luteinizing hormone surge. ${ }^{17} \mathrm{AR}$ expression levels in the myometrium are also maintained at higher levels during early proliferative and synthetic phases of pregnancy. ${ }^{18}$ We have shown that while positively regulating IGF-1 receptor protein stability, AR is an important regulator of myometrial cell cycling and cell proliferation. ${ }^{18}$ These findings are further supported by studies on female AR knockout mice. ${ }^{19}$ Loss of function of AR results in a subinfertile phenotype with a thinner uterine myometrial wall and reduced myometrial cell numbers when compared with wild-type mice, indicating that $A R$ is also a regulator of myometrial growth during uterine development. As the balance between cell proliferation and cell death determines myometrium tissue growth, we propose that AR may also have an antiapoptotic role in myometrial cells.

\section{Results}

AR protein levels determine the responses of human myometrial smooth muscle cells to apoptotic stimuli. To test the potential role of AR in myometrial cell apoptosis, we used human myometrial cells with either overexpression or RNA silencing of AR as described. ${ }^{18}$ These cells are referred to as hTERT(AR), hTERT(Mock), hTERT(shAR) and hTERT(shCTRL). Their AR protein expression levels were shown in Supplementary Figure S1. These myometrial cells were exposed to Camptothecin (CPT) or UV light as intrinsic apoptosis stimuli or Anti-Fas antibody as an extrinsic stimulus. Cell apoptosis were detected by two independent methods, which are the levels of cleaved PARP1 (c-PARP1) or cleaved caspase 3 (c-CASP3) detected by western blotting and cell populations that bind Annexin $\mathrm{V}$ measured by fluorescence-activated cell sorting (FACS) assay. By measuring c-PARP1 levels, we showed that CPT induced myometrial cell apoptosis in a dose-dependent manner (Figure 1a). Enhanced AR expression reduced the cellular apoptotic response, whereas AR knockdown rendered myometrial cells more sensitive to CPT-induced apoptosis. These results are consistent with the cell apoptosis assay measuring the cell population that bind Annexin $V$ (Figure $1 \mathrm{~b}$ ). We also used $2.5 \mu \mathrm{g} / \mathrm{ml}$ of CPT to induce cell apoptosis in a $0-30 \mathrm{~h}$ time course. Both c-PARP1 levels and Annexin $V$ binding showed that AR antagonized CPTinduced apoptotic cell death (Figures $1 \mathrm{c}$ and d). To further confirm the protective role of $A R$, we also induced apoptosis by UV light. Human myometrial cells were exposed to $0-5 \mathrm{~mJ} / \mathrm{cm}^{2}$ followed by 16 -hour recovery (Figures $2 \mathrm{a}$ and $\mathrm{b}$ and Supplementary Figure S2), or to $3.5 \mathrm{~mJ} / \mathrm{cm}^{2}$ of UV light followed by $0-30 \mathrm{~h}$ recovery (Figures $2 \mathrm{c}$ and $\mathrm{d}$ ). We observed that AR antagonized cellular apoptosis induced by UV light. Furthermore, we assess the impact of triggering the extrinsic apoptotic pathway in myometrial cells by the anti-Fas antibody. Myometrial cells were treated with 0-500 ng/ml of anti-Fas antibody (clone $\mathrm{CH} 11$ ) for $24 \mathrm{~h}$ (Figures $3 a$ and b), or with $300 \mathrm{ng} / \mathrm{ml}$ of Fas antibody for $0-48 \mathrm{~h}$ (Figures $3 \mathrm{c}$ and d). ${ }^{20}$ Both c-CASP3 levels and Annexin $V$ binding were measured. Cells with enhanced AR expression were more resistant, whereas cells with AR silencing were more sensitive to anti-Fas antibody induced a
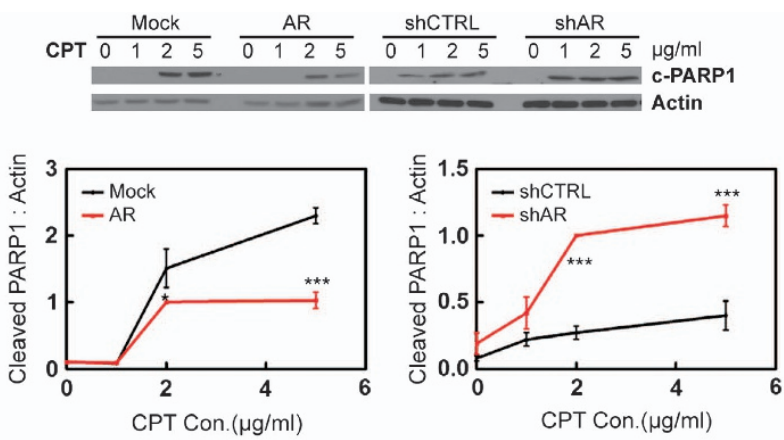

b
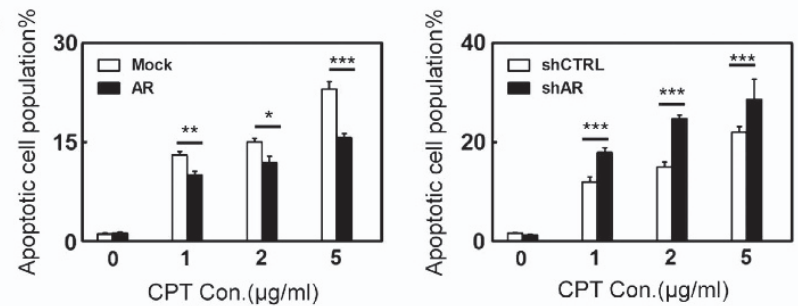

C
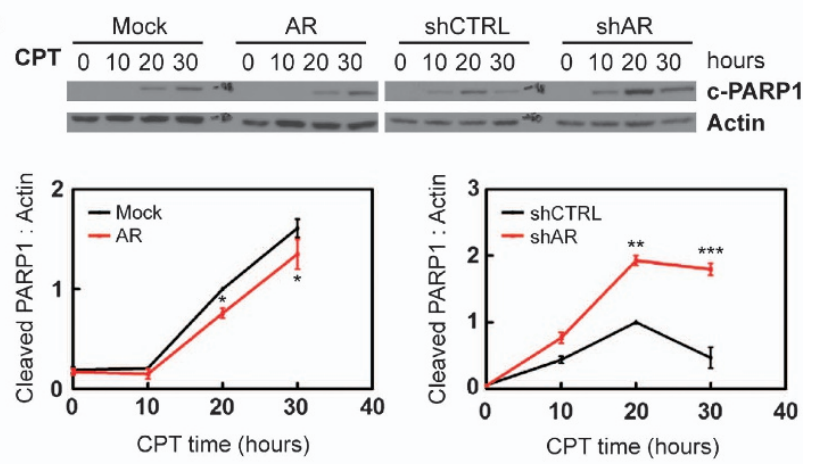

d
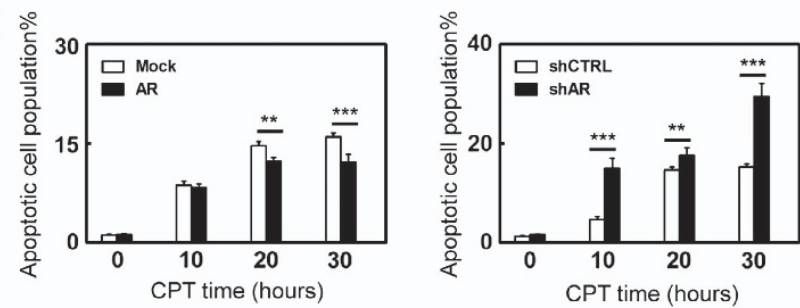

Figure 1 Human myometrial cells hTERT(Mock), hTERT(AR), hTERT(shCTRL) or hTERT(shAR) cells were cultured in DMEM plus $5 \%$ charcoal-stripped serum. Cells were treated with $0,1,2,5 \mu \mathrm{g} / \mathrm{ml}$ of camptothecin (CPT) for $24 \mathrm{~h}$ (a and $\mathbf{b}$ ) or with $2.5 \mu \mathrm{g} / \mathrm{ml}$ of CPT for $0,10,20,30 \mathrm{~h}$ (c and d). Representative western blot and densitometry analysis on data from triplicate experiments on C-PARP1 protein levels relative to actin were expressed as mean \pm S.E.M (a and $\mathbf{c}$ ). FACS assays measured cell populations that bind Annexin $V$ from triplicate experiments ( $n=2 /$ repeat) and were expressed as mean \pm S.E.M. (b and d). Student's $t$-test was performed with * as $P<0.05$; ${ }^{* *}$ as $P<0.01$ and ${ }^{\star * \star}$ as $P<0.001$

apoptosis. In summary, these results indicate that AR has a protective role to prevent myometrial cells from apoptotic cell death.

AR agonist protects human myometrial smooth muscle cells from apoptotic stimuli. The function of AR can be mediated through either receptor-dependent or liganddependent pathways. ${ }^{21}$ To study the hormonal regulation of 
a
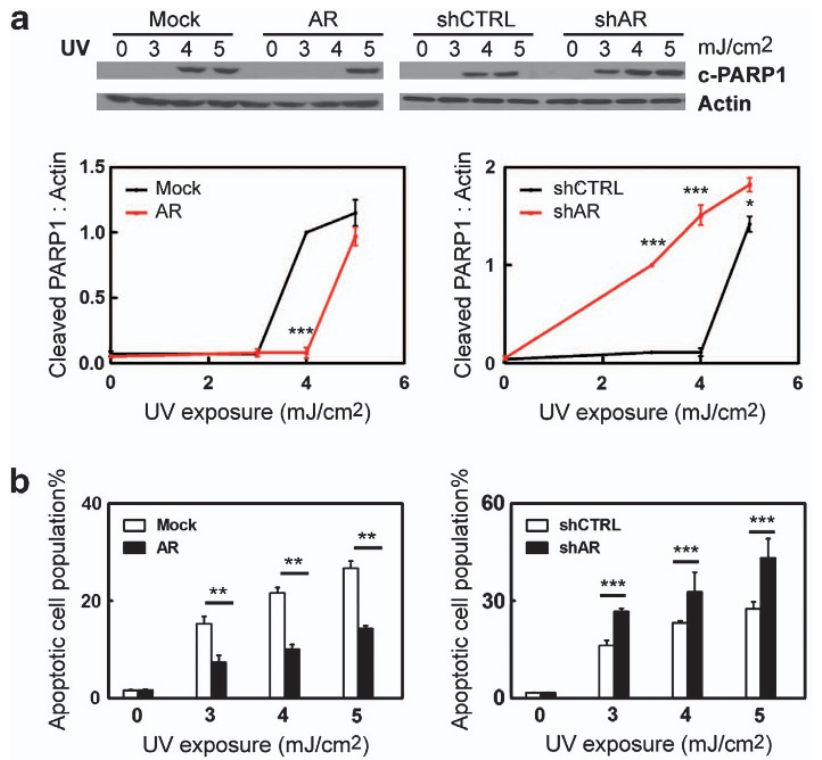

C
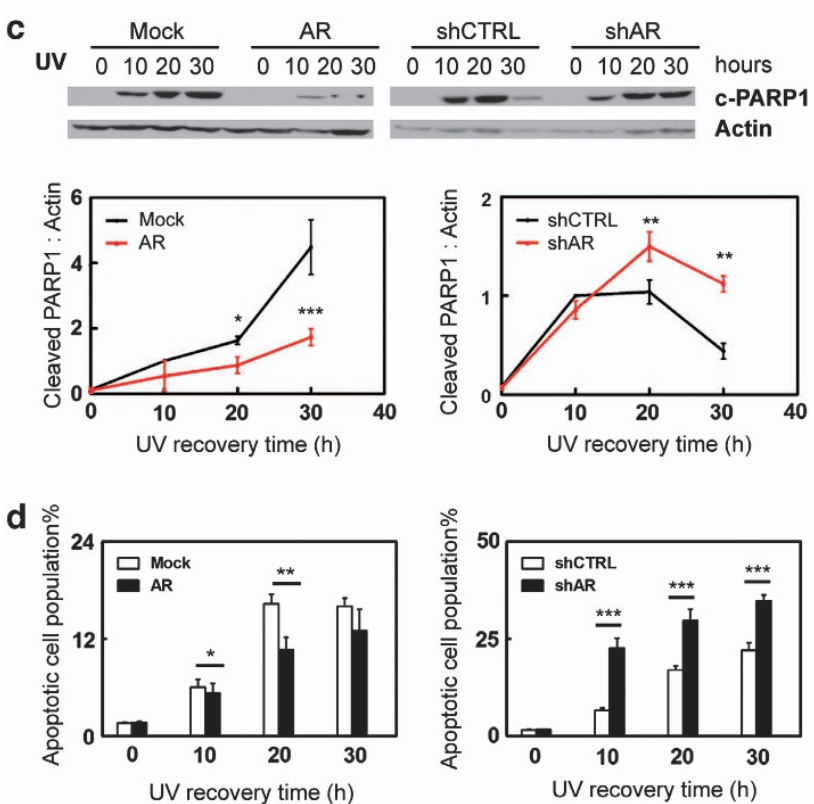

Figure 2 Human myometrial cells hTERT(Mock), hTERT(AR), hTERT(shCTRL) or hTERT(shAR) cells were cultured in DMEM plus $5 \%$ charcoal-stripped serum. Cells were exposed to $0,3,4,5 \mathrm{~mJ} / \mathrm{cm}^{2} \mathrm{UV}$ light and allowed to recover for $24 \mathrm{~h}$ (a and $\mathbf{b}$ ) or to $3.5 \mathrm{~mJ} / \mathrm{cm}^{2}$ and allowed to recover for 0 , $10,20,30 \mathrm{~h}$ (c and d). Representative western blot and densitometry analysis on data from triplicate experiments on c-PARP1 protein levels relative to actin were expressed as mean \pm S.E.M. (a and $\mathbf{c}$ ). FACS assays measured cell populations that bind Annexin V from triplicate experiments ( $n=2 /$ repeat) and were expressed as mean \pm S.E.M. (b and $\mathbf{d}$ ). Student's $t$-test was performed with * as $P<0.05$; ** as $P<0.01$ and ${ }^{* * *}$ as $P<0.001$

AR in myometrial cell apoptosis, we treated parental hTERT-HM cells with CPT, UV light or anti-Fas antibody in the presence of vehicle, synthetic AR agonist R1881 or AR antagonist MDV3100 (Figures $4 \mathrm{a}-\mathrm{c}$ ) for 0-48h. Cell apoptosis was again measured by the levels of c-PARP1 or c-CASP3. We showed that R1881 significantly reduced the levels of c-PARP1 under CPT and UV light treatments
(Figures 4a and b). In addition, MDV3100 treatment resulted in higher levels of c-PARP1 when compared with cells under R1881 treatment. We also showed that R1881 decreased, whereas MDV3100 increased c-CASP3 levels in myometrial cells, when cells were challenged by anti-Fas antibody (Figure 4c). These data were further confirmed by FACS assays measuring Annexin $\mathrm{V}$ binding, when myometrial cells were exposed to CPT, UV light and the anti-Fas antibody (Supplementary Figure S3). These results demonstrated that in addition to AR protein, the antiapoptotic function of $A R$ can also be modulated by AR ligands.

Gene microarray analyses of AR-regulated genes. To identify AR-targeted genes that are responsible for its antiapoptotic action, we performed gene microarray analyses. In total, 1567 genes were significantly changed by AR knockdown (>1.5 fold). Gene ontology (GO) analyses by The Database for Annotation, Visualization and Integrated Discovery (DAVID) version 6.7 further characterized the key cellular processes regulated by $\mathrm{AR}$. The top two ranked GO terms are cell cycling and apoptosis, which involve a total of 201 genes (Figure 5a). These results further confirmed that the main functions of $A R$ in myometrial cells are to regulate cell proliferation and apoptosis. Information of the top-ranked 30 genes by q-value either up- or downregulated by AR knockdown are also listed in Figure $5 \mathrm{~b}$. Using the IPA software (Ingenuity Systems), we further identified three major signaling cascades that are regulated by AR and may mediate AR antiapoptotic function (Figure 5c). They are protein factors within the EGF signaling (EGF, SHC, PKC, GRB2 and RASA), RNA splicing factors (SRSF1, SRSF2, SRSF4, hnRNPM and hnRNPU) and proteins involving in DNA repair (XRCC5, XRCC6, PARP1, NONO). The EGF signaling is particularly interesting as its downstream effector, Akt, is well known for its antiapoptotic function. Using real-time PCR to validate microarray findings, we showed that mRNA levels of EGF, SHC, PKC, GRB2 and RASA genes were significantly reduced in the presence of AR knockdown (Figure 5d), and upregulated by enhanced AR expression. It should be noted that mRNA levels of these genes were not altered by $\mathrm{R} 1881$ treatment, indicating that $A R$ regulation of EGF signaling is receptor-dependent.

Antiapoptotic action of the AR is mediated through a receptor-dependent mechanism. $A R$ regulates several protein components within the EGF signaling, suggesting that AR may exert its antiapoptotic function by modulating EGF signaling. To test this hypothesis, we first treated hTERT(shCTRL) and hTERT(shAR) cells with 0,5 and $10 \mathrm{ng} / \mathrm{ml}$ of recombinant EGF for $30 \mathrm{~min}$. Activation of EGF signaling led to increased phospho-SHC (p-SHC) and phospho-Akt (p-Akt), whereas AR knockdown attenuated these changes (Figure 6a). Within the antiapoptotic Bcl2 family, very low levels of $\mathrm{Bcl} 2$ protein was expressed in the myometrial cells. There were no changes of $\mathrm{Bcl}-\mathrm{xL}$ protein levels in response to EGF treatment or to AR silencing. However, a robust upregulation of $\mathrm{Mcl}-1$ was induced by EGF, concurrent with the activation of Akt signaling, suggesting that the antiapoptotic function of AR may be mediated through the Akt signaling to upregulate $\mathrm{Mcl}-1$ 

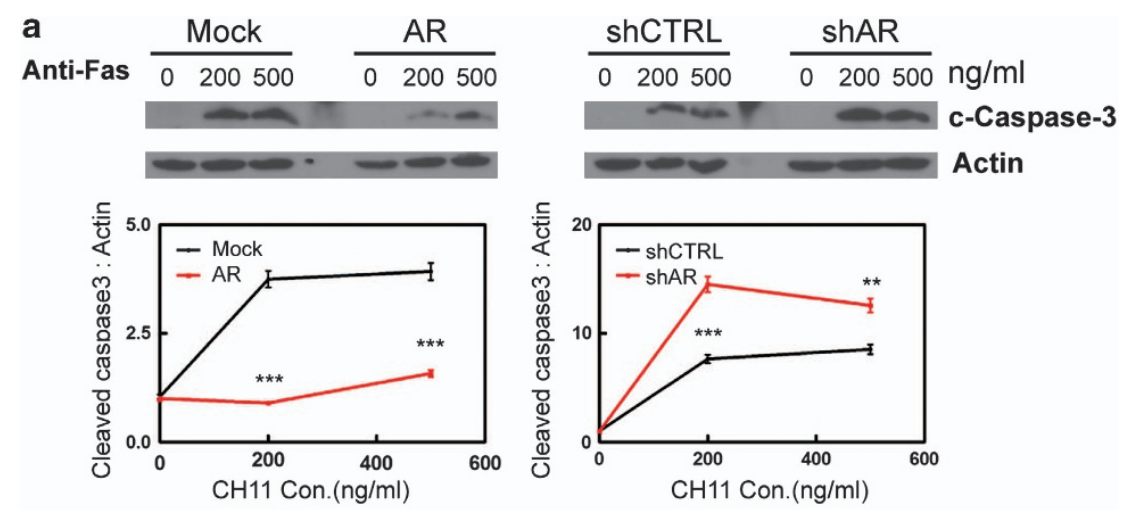

b
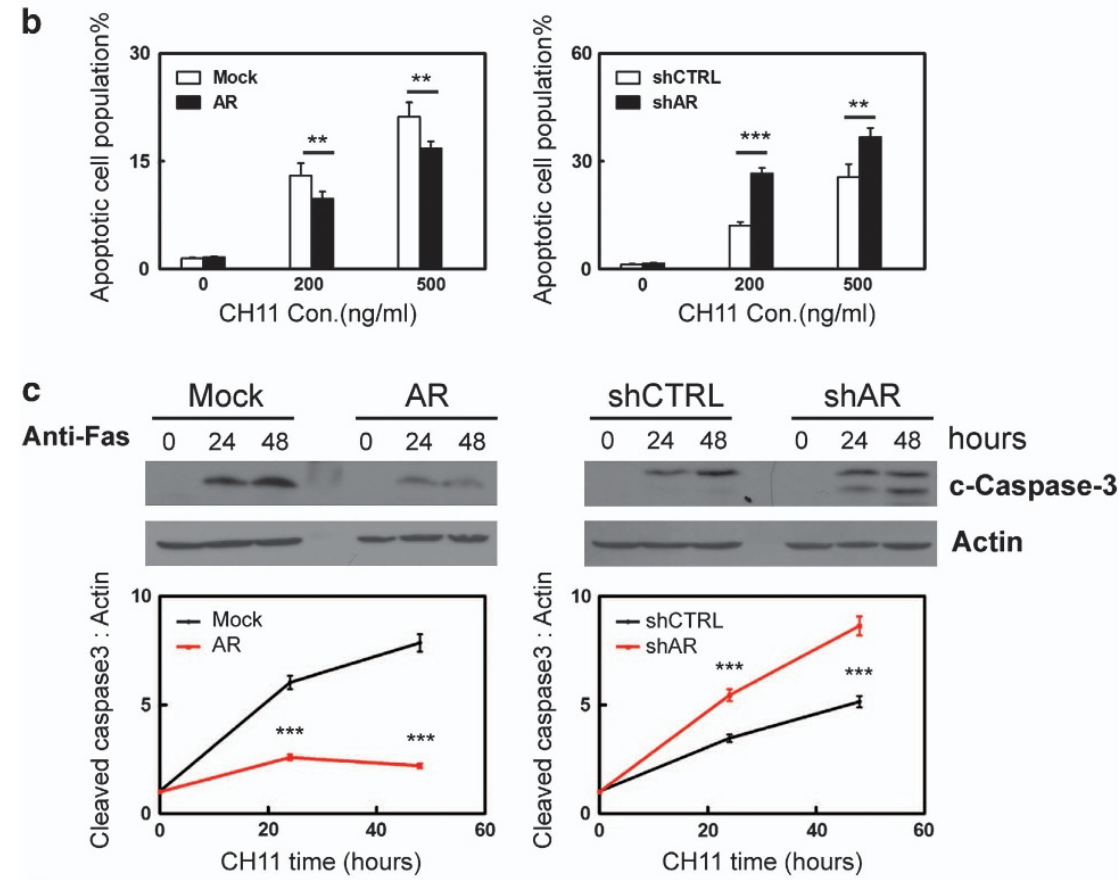

d
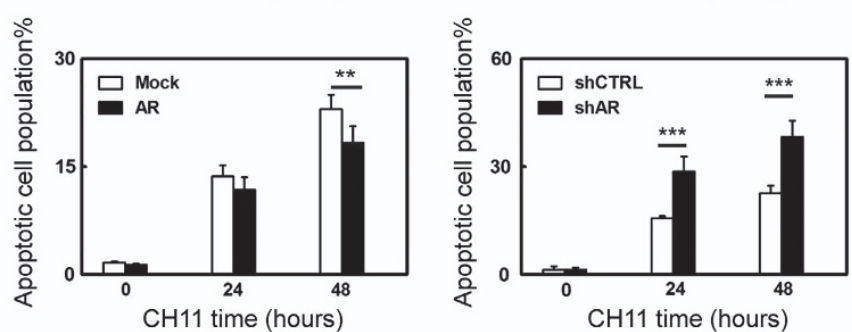

Figure 3 Human myometrial cells hTERT(Mock), hTERT(AR), hTERT(shCTRL) or hTERT(shAR) cells were cultured in DMEM plus $5 \%$ charcoal-stripped serum. Cells were treated with 0,200 or $500 \mathrm{ng} / \mathrm{ml}$ anti-Fas antibody for $24 \mathrm{~h}$ (a and $\mathbf{b}$ ) or with $300 \mathrm{ng} / \mathrm{ml}$ of anti-Fas antibody for 0,24 or $48 \mathrm{~h}$ (c and d). Representative western blot and densitometry analysis on data from triplicate experiments on c-CASP3 protein levels relative to actin were expressed as mean \pm S.E.M. (a and c). FACS assays measured cell population that bind Annexin $V$ from triplicate experiments $(n=2 /$ repeat) and were expressed as mean \pm S.E.M. (b and $\mathbf{d})$. Student's $t$-test was performed with * as $P<0.05$; ** as $P<0.01$ and ${ }^{* *}$ as $P<0.001$

protein levels. To test this possibility, we applied the PI3K/Akt inhibitor, LY294002 to the myometrial cells. Blocking Akt activity dramatically reduced $\mathrm{Mcl}-1$ protein levels (even in the presence of EGF treatment) accompanied by enhanced cellular apoptosis as measured by c-PARP1 levels (Figure 6b). These results indicate that in myometrial cells, AR utilizes EGF/Akt signaling to control Mcl-1 expression and exert an antiapoptotic function.
It is known that EGF treatment can also activate Src kinase to exert antiapoptotic function. ${ }^{22}$ To test whether this mechanism also exists in myometrial cells, we co-treated hTERT(shCTRL) and hTERT(shAR) cells with EGF plus PP2, a Src inhibitor (Figure 6c). We observed that although phosphorylation of Src is efficiently blocked, Mcl-1 and c-PARP1 protein levels were not altered, unless RNA silencing of $A R$ was present. These results indicate that the 
a

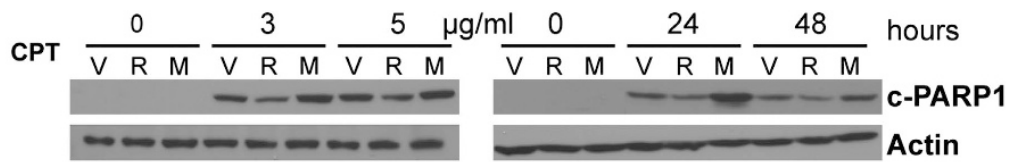
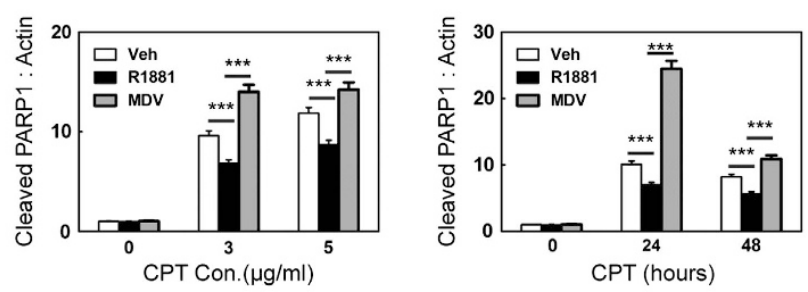

b
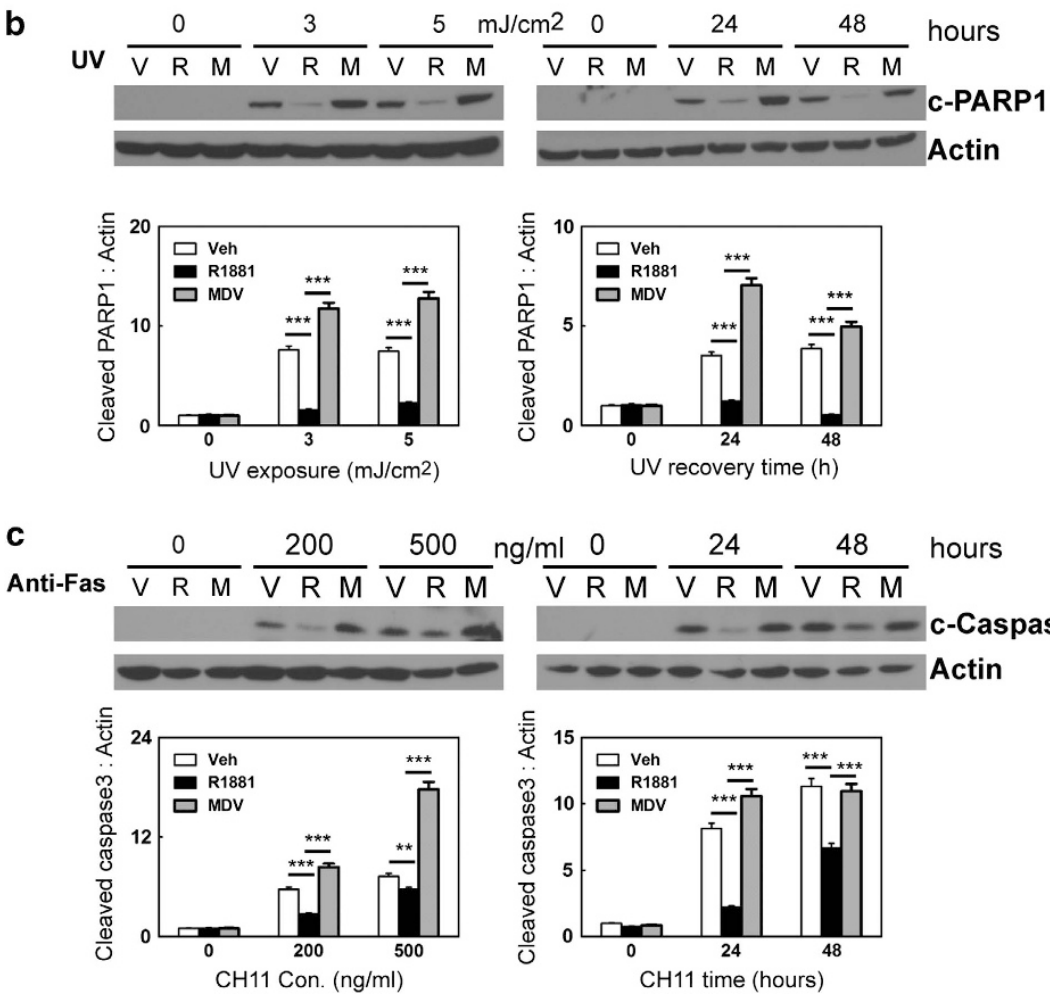

Figure 4 hTERT-HM cells were cultured in DMEM with $5 \%$ charcoal-stripped serum and treated with vehicle, $10 \mathrm{nM}$ of R1881 or $20 \mathrm{uM}$ of MDV3100. (a) Cells were also co-treated with 0,3 or $5 \mu \mathrm{g} / \mathrm{ml}$ of CPT for $24 \mathrm{~h}$ or with $2.5 \mu \mathrm{g} / \mathrm{ml}$ for 0,24 or $48 \mathrm{~h}$. (b) Cells were co-treated with 0,3, or $5 \mathrm{~mJ} / \mathrm{cm}^{2} \mathrm{UV}$ light and allowed to recover for $24 \mathrm{~h}$ or with $3.5 \mathrm{~mJ} / \mathrm{cm}^{2}$ and allowed to recover for 0,24 or $48 \mathrm{~h}$. (c) Cells were co-treated with 0, 200 or $500 \mathrm{ng} / \mathrm{ml}$ anti-Fas antibody for $24 \mathrm{~h}$ or with $300 \mathrm{ng} / \mathrm{ml}$ of anti-Fas antibody for 0,24 or $48 \mathrm{~h}$. Representative western blot and densitometry analysis on data from triplicate experiments on c-PARP1 or c-CASP3 protein levels relative to actin were expressed as mean \pm S.E.M. Student's $t$-test was performed with * as $P<0.05 ;{ }^{* *}$ as $P<0.01$ and ${ }^{* *}$ as $P<0.001$

AR-dependent antiapoptotic function is dominant through the EGF-Akt signaling pathway.

To further confirm that $\mathrm{Mcl}-1$ serves as the downstream effector for the antiapoptotic function of $A R$, we treated myometrial cells with siRNA for Mcl-1 (Figure 6d). RNA silencing of $\mathrm{Mcl}-1$ resulted in increased c-PARP1 levels in hTERT(shCTRL) cells regardless of the phospho-Akt status. As Mcl-1 protein levels were lower and c-PARP1 level were higher in hTERT(shAR) cells, Mcl-1 knockdown did not show any impact on c-PARP1 levels in hTERT(shAR) cells. We also treated cells with MIM1, a specific inhibitor of $\mathrm{Mcl}-1$ that selectively targets the $\mathrm{BH} 3$ domain of $\mathrm{Mcl}-1$ protein. ${ }^{23}$ MIM1 treatment increased c-PARP1 levels, even when the myometrial cells expressed high levels of phospho-Akt.
Although enhanced AR expression resulted in elevated protein levels of Mcl-1, treatment of siRNA to Mcl-1 or MIM1 can antagonize AR's impact, resulting in higher levels of c-PARP1 (Figure 6e). Together, these results led us to conclude that by modulating the EGF-Akt-Mcl-1 signal pathway, AR exerts an antiapoptotic function in an AR-dependent manner.

Antiapoptotic action of the AR can also be mediated through a ligand-dependent mechanism. Ligand-activated $A R$ can recruit and activate Src kinase, a potential mechanism for the ligand-dependent antiapoptotic action of the AR. To test this hypothesis, we first treated parental hTERT-HM cells with either vehicle or R1881. Although the 
a

\begin{tabular}{lcc}
\hline GO TERM & Gene numbers & -LOG(p-value) \\
\hline cell cycle & 102 & 1.48 \\
cell apoptosis & 99 & 1.64 \\
cell proliferation & 96 & 2.99 \\
protein localization & 95 & 3.09 \\
regulation of macromolecule & & \\
metabolic process & 86 & 1.38 \\
RNA processing & 76 & 3.37 \\
response to organic & & \\
substance & 75 & 3.23 \\
oxidation reduction & 73 & 6.48 \\
regulation of cellular & & \\
biosynthetic process & 71 & 3.94 \\
vellular response to stress & 65 & 3.38 \\
DNA repair & 59 & 5.49 \\
vesicle-mediated transport & 58 & 5.65 \\
response to wounding & 53 & 7.39 \\
\hline
\end{tabular}

\section{b}

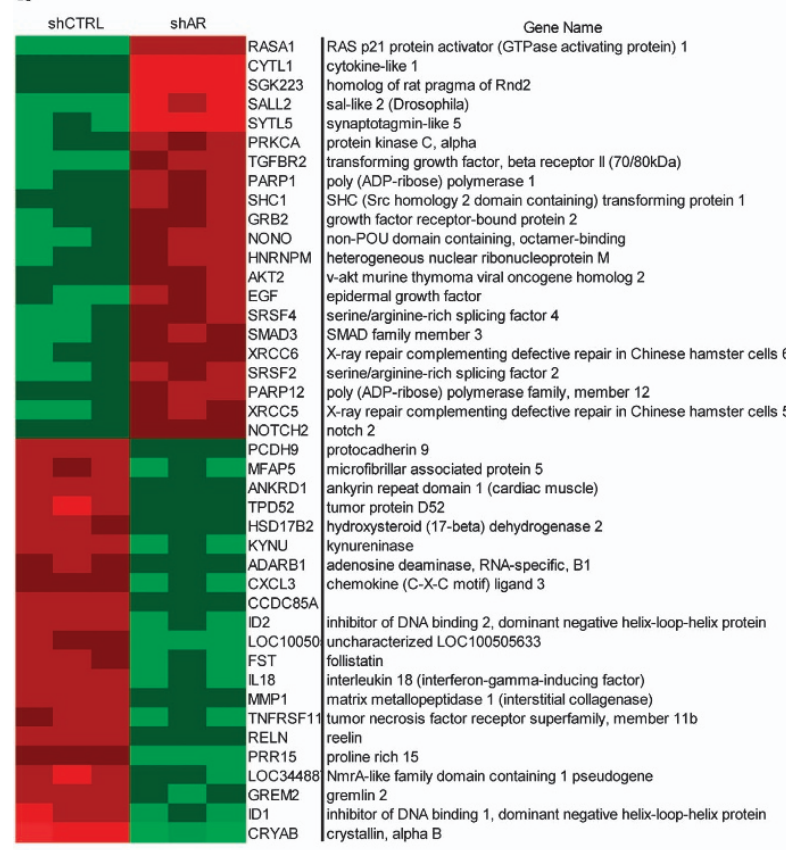

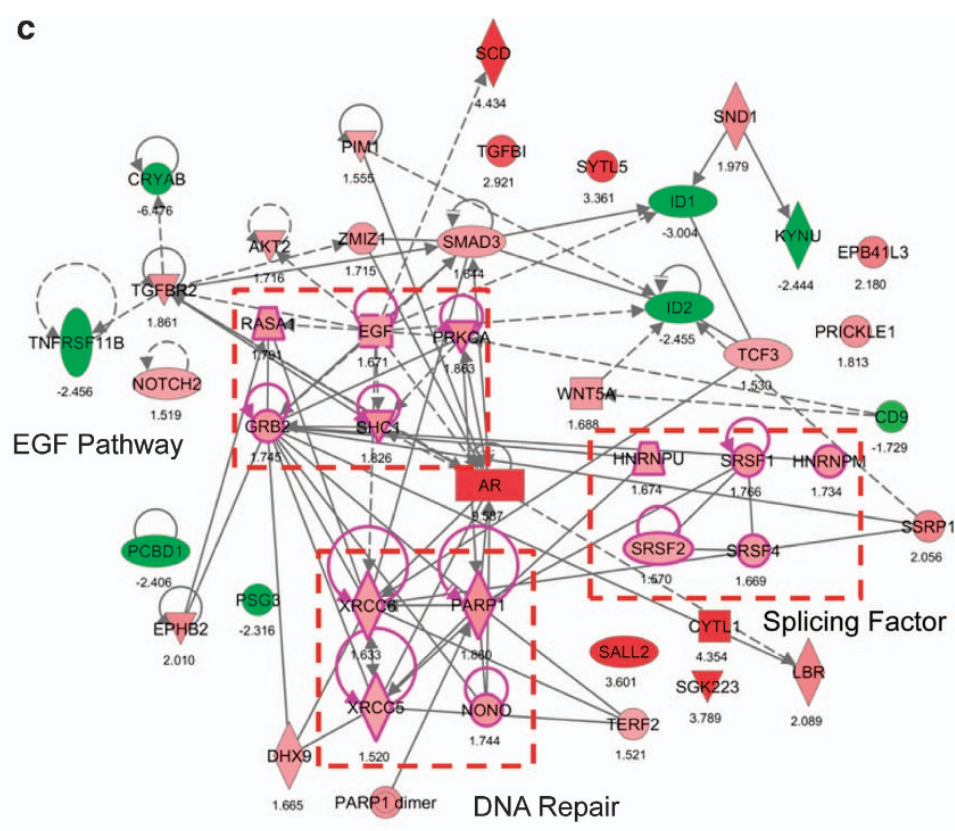

d
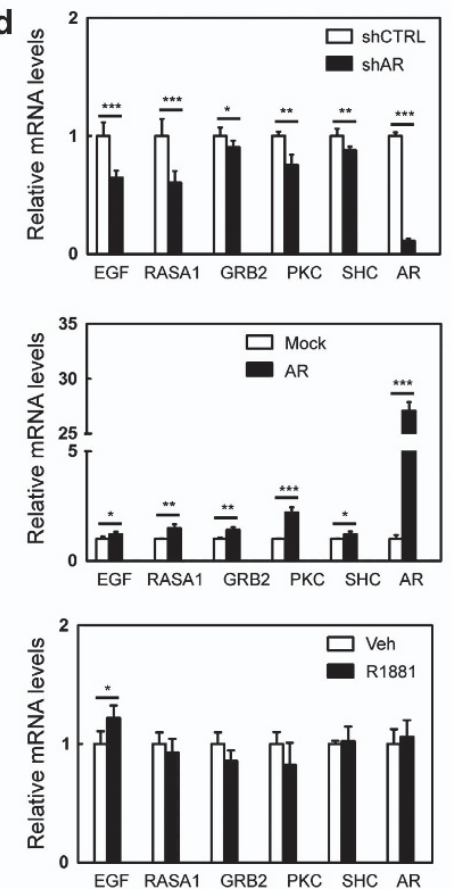

Figure 5 (a) Go-term analyses by DAVID (version 6.7) identified top 15 ranked gene groups regulated by AR. (b) Information on top 30 ranked genes that either upregulated or downregulated by AR were listed. (c) IPA identified canonical connection of signaling pathways regulated by AR. (d) Real-time PCR validate mRNA levels of components of EGF signaling in hTERT(shCTRL), hTERT(shAR), hTERT(mock) and hTERT(AR) cells or hTERT-HM cells treated with vehicle or $10 \mathrm{nM} \mathrm{R} 1881$

EGF-Akt pathway is not altered (no changes in $\mathrm{p}-\mathrm{SHC}$ and p-Akt levels), R1881 stimulated phosphorylation of Src and its downstream effector STAT3, but not STAT5 (Figure 7a and Supplementary Figure S5). As one of the downstream targeted genes of STAT3, Mcl-1 expression was also upregulated by R1881 treatment. By contrast, there were no changes of $\mathrm{Bcl} 2$ and $\mathrm{Bcl}-\mathrm{xL}$, two other antiapoptotic Bcl2 family members. We further demonstrated that R1881induced activation of Src was effectively inhibited by PP2, resulting in decreased phosphorylation of STAT3. We also observed subsequent downregulation of $\mathrm{Mcl}-1$ expression and increased levels of c-PARP1 protein even in the presence of R1881 (Figure $7 \mathrm{~b}$ ). We have also applied the STAT3 inhibitor, WP1066, to show that transcriptional activity of STAT3 induced by R1881 was directly associated with Mcl-1 protein levels (Figure $7 \mathrm{c}$ ). Blocking the activation of STAT3 resulted in decreased protein levels of $\mathrm{Mcl}-1$ and higher levels of c-PARP1 in the presence of R1881 
a

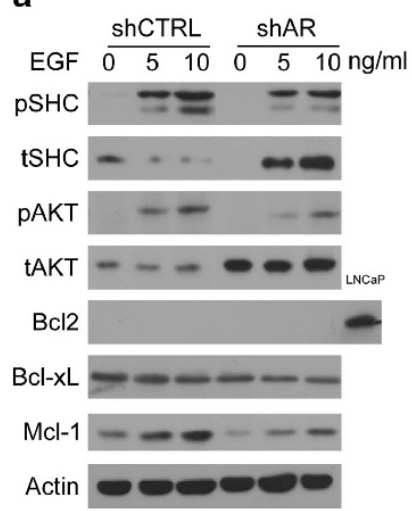

b

UV+EGF ShCTRL ShAR

LY294002 - + +

pAKT

tAKT

Mcl-1

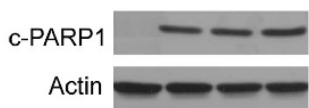

C

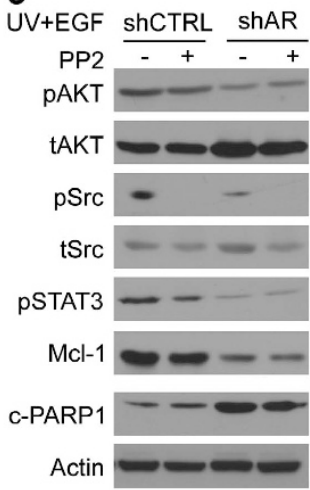

d UV+EGF ShCTRL ShAR

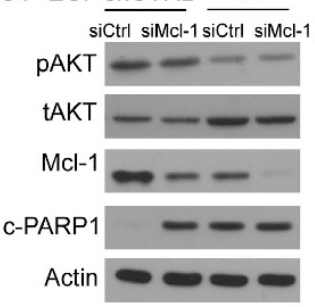

e UV+EGF $\underline{\text { ShCTRL }} \underline{\text { ShAR }}$

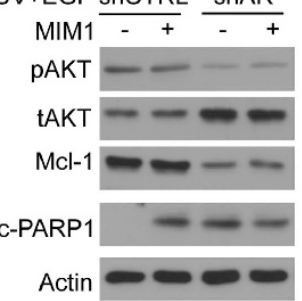

f UV+EGF Mock AR
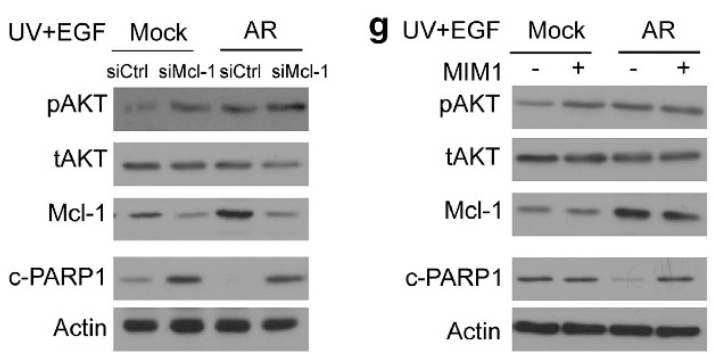

Figure 6 (a) hTERT(shCTRL) and hTERT(shAR) cells were treated with $0,5,10 \mathrm{ng} / \mathrm{ml}$ recombinant EGF peptide for 30 min. Cell lyses were collected. (b-e) hTERT(shCTRL) and hTERT(shAR) cells were treated with vehicle, $50 \mu \mathrm{M}$ of LY294002 (b), $4 \mu \mathrm{M}$ of PP2 (c), siRNA for Mcl-1 (d) or $20 \mu \mathrm{M}$ of MIM1 (e) for $16 \mathrm{~h}$, after which cells were co-treated with $10 \mathrm{ng} / \mathrm{ml}$ of EGF and exposed to $3.5 \mathrm{~mJ} / \mathrm{cm}^{2}$ of UV light. After recovery for $24 \mathrm{~h}$, cell lyses were collected. hTERT(mock) and hTERT(AR) cells were transfected with siRNA for Mcl-1 (f) or MIM1 (g) for $24 \mathrm{~h}$ and then subjected to $10 \mathrm{ng} / \mathrm{ml}$ of EGF and exposed to $3.5 \mathrm{~mJ} / \mathrm{cm}^{2}$ of UV light. After recovery for $24 \mathrm{~h}$, cell lyses were collected. Western blotting assays were performed with antibodies as indicated. Representative blots from triplicate experiments were presented. Note: Bcl2 is expressed in extremely low levels in myometrial cells as shown in Figure 6a. Protein lysate from LNCaP cells was used as a positive control for immunoreactivity to Bcl2 antibody

treatment. We further showed that $\mathrm{Mcl}-1$ is the downstream effector of STAT3. Mcl-1 knockdown or inhibition of Mcl-1 activity by MIM1 resulted in higher levels of c-PARP1 protein, even in the presence of Src and STAT3 activations by R1881 (Figure $7 \mathrm{~d}$ ). We conclude from this set of experiments that AR can also exert its antiapoptotic function in a liganddependent manner through the Src-STAT3-Mcl-1 signaling pathway.

\section{Discussion}

The functions of myometrium during pregnancy and labor are not only to provide an environment for the fetus to fully develop, but also to contract at labor to expel the fetus into the extrauterine environment. Owing to the complexity of these multiple tasks, the myometrium has to adapt into different phenotypes to achieve these goals in a coordinated fashion with the progression of pregnancy. Therefore, we have proposed the myometrial phenotype programming concept to address the phenotypic plasticity of this organ. Our findings presented here for the first time characterized the antiapoptotic function of the AR signaling in human myometrial cells. By revealing the molecular mechanisms by which AR signaling mediates such functions by both receptor-dependent and ligand-dependent pathways, we further strengthen the notion that the AR signaling is a critical component of myometrial phenotype programming.

Our studies support the dual roles of $A R$ in regulating myometrial cell proliferation and resistance to apoptotic stimuli. This conclusion is supported by the AR gestational profile. High levels of AR protein were observed during the proliferative phase of pregnancy, but decreased dramatically as labor was approached. ${ }^{18}$ This expression pattern is controlled by the mechanical stretch induced by growing fetus as well as estrogen/progesterone signaling. ${ }^{18}$ Furthermore, AR utilizes different signaling pathways to control proliferation and apoptosis of myometrial cells. The proliferative action of $A R$ is ligand-independent. We have shown that AR protein is 
required for IGF-1R protein stability and regulates downstream phosphorylation of Akt. ${ }^{18}$ High levels of AR during early pregnancy are associated with enhanced activation of IGF-1 downstream effectors, including IRS-1, phosphomTOR and phospho-S6K1 in the pregnant rat myometrium. ${ }^{24}$ However, the antiapoptotic function of AR is both liganddependent and receptor-dependent (Figure 8). In the receptor-dependent pathway, AR but not androgen controls transcription of several components of the EGF signaling including EGF, RASA, GRB2 and SHC (Figure 6). EGF signaling cannot be effectively activated in the presence of AR knockdown. In the ligand-dependent pathway, AR agonist R1881 does not affect PI3K/Akt pathway. Rather, it triggers the activation of Src kinase and the transcription factor STAT3, resulting in an increase of $\mathrm{Mcl}-1$ expression (Figure 7). Interestingly, EGF signaling also activates Src kinase and STAT3 (Supplementary Figure S4), suggesting that Src and STAT3 may possibly induce $\mathrm{Mcl}-1$ protein levels. However, our further investigation shows that although EGF induced-Src activation can be blocked by PP2, it does not effectively decrease Mcl-1 levels. In contrast, PI3K/Akt inhibitor LY294002 dramatically abolishes $\mathrm{Mcl}-1$ levels and induces c-PARP1. These results indicate that under EGF signaling, Akt activation has the dominant role over Src-STAT3 in mediating AR antiapoptotic function (Figure 8). a

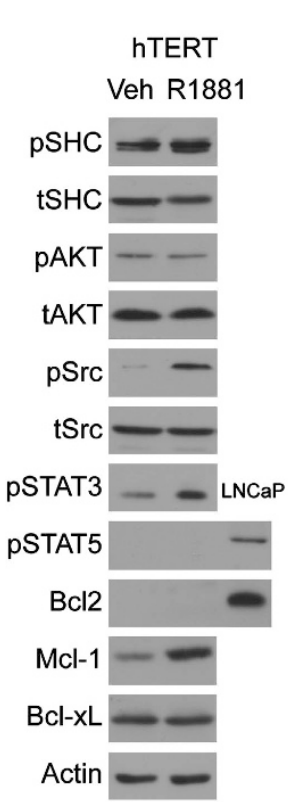

b

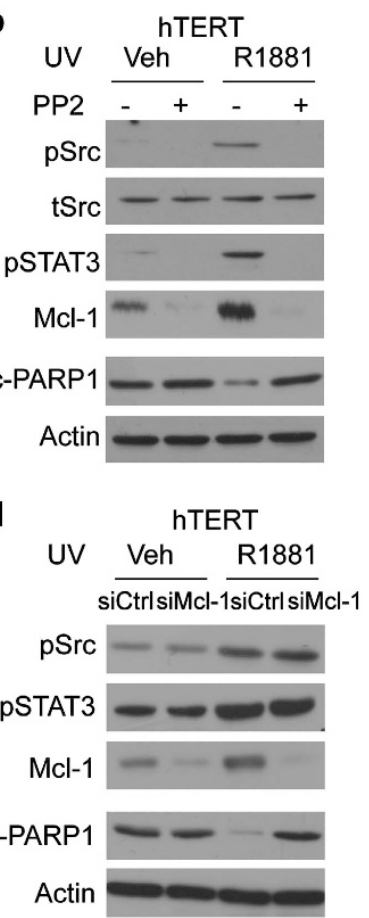

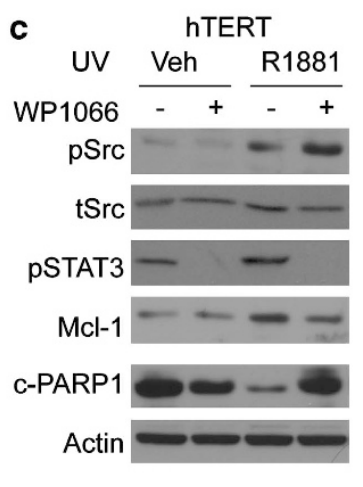

e

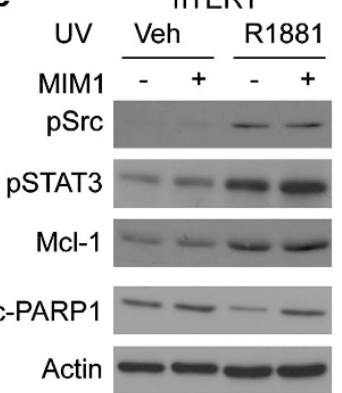

Figure 7 Human myometrial cells, hTERT-HM, were cultured in DMEM medium containing $5 \%$ charcoal-stripped serum for $48 \mathrm{~h}$. (a) Cells were treated with vehicle or $10 \mathrm{nM}$ R1881 for $16 \mathrm{~h}$. Protein lyses were collected. (b-e) Cells were exposed to $3.5 \mathrm{~mJ} / \mathrm{cm}^{2}$ UV light in the presence of $\pm 10 \mathrm{nM}$ of R1881. Cells were also treated with vehicle, $4 \mu \mathrm{M}$ of PP2 (b), $5 \mu \mathrm{M}$ of WP1066 (c), siRNA for Mcl-1 (d) or $20 \mu \mathrm{M}$ of MIM1 (e) for $16 \mathrm{~h}$. Protein lyses were collected and immunoblotted with antibodies as indicated. Representative blots from triplicate experiments were presented. Note: STAT5 and Bcl2 are expressed in extremely low levels in myometrial cells as shown in Figure 7a. Protein lysis from LNCaP cells was used as a positive control for immunoreactivity to phosphor-STAT5 and Bcl2 antibodies

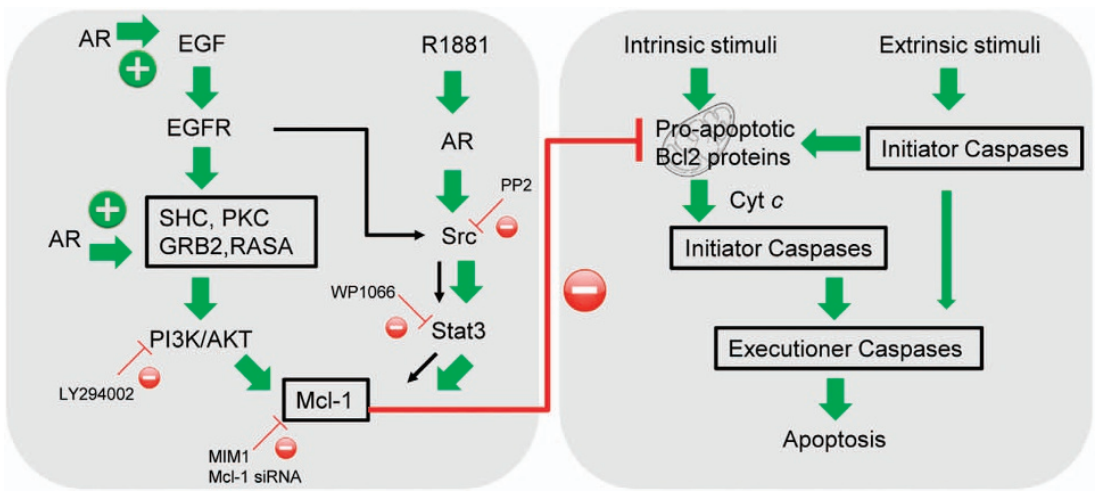

Figure 8 Proposed mechanisms by which AR exert its antiapoptotic function in human myometrial cells 
AR signaling involves both intrinsic and extrinsic pathways of cellular apoptosis. The common feature of both pathways is that apoptotic stimuli activate initiator caspases $8 / 10$ for the extrinsic pathway or initiator caspase 9 for intrinsic pathway. ${ }^{25}$ The initiator caspases then activate the executioner caspases (e.g. caspases 3, 6 and 7) to cleave death substrate. Our studies indicate that $\mathrm{AR}$ controls $\mathrm{Mcl}-1$ expression through either EGF/Akt or Src/STAT3 pathways. Mcl-1 is known to prevent the activation of the pro-apoptotic proteins, Bax and BAK. ${ }^{26}$ Furthermore, Akt can phosphorylate and inactivate the pro-apoptotic BAD protein. ${ }^{14}$ Therefore, the AR/Mcl-1 axis inhibits activation of caspase 9 activation and subsequent executioner caspases to supress the intrinsic apoptosis pathway. The intrinsic pathway can also serve as an enhancer for the extrinsic pathway and facilitate cell apoptosis by the extrinsic pathway. This mechanism had been demonstrated in studies showing that enhanced expression of antiapoptotic Bcl2 family members blocked death receptor-mediated activation of caspase 8 and downstream executioner caspases. ${ }^{27}$ The same principle is also applied to myometrial cells. AR agonist, through upregulation of $\mathrm{Mcl}-1$ expression, can inhibit the activation of executioner caspases that are triggered by the extrinsic apoptotic pathway.

Our findings support the critical role of $\mathrm{Mcl}-1$ in protecting myometrial cells from apoptotic cell death. Activation of caspase 3 is required to maintain uterine quiescence through fragmentation of uterine myocyte contractile proteins. ${ }^{28}$ Upregulation of $\mathrm{Mcl}-1$ was demonstrated to be used by myometrial cells to neutralize the apoptotic property of caspase $3 .^{28}$ In our studies, we also find Mcl-1 has a unique role in mediating AR antiapoptotic function in myometrial cells, as other antiapoptotic the expression of Bcl2 family members, such as Bcl2 and $\mathrm{Bcl}-\mathrm{xL}$, is not affected by the AR signaling. This phenomenon is consistent with reports in human macrophages, where the antiapoptotic action of Akt is specifically mediated by $\mathrm{Mcl}-1$, but not by $\mathrm{Bcl} 2$ or $\mathrm{Bcl}-\mathrm{xL}^{29}$

We report that AR utilizes multiple signaling cascades (e.g. Akt and Src/STAT3) to induce $\mathrm{Mcl}-1$ expression in myometrial cells. As the expression of $\mathrm{Mcl}-1$ is regulated by both transcriptional and posttranslational levels, Akt can trigger its downstream mTOR pathway to enhance $\mathrm{Mcl}-1$ protein translation. ${ }^{30,31}$ Akt can also enhance $\mathrm{Mcl}-1$ protein stability through modulating phosphorylation of GSK3. ${ }^{32}$ Furthermore, Akt can rapidly induce $\mathrm{Mcl}-1$ gene transcription by regulating Akt-dependent transcription factors. ${ }^{33}$ Ligand-activated AR can recruit and activate Src kinase ${ }^{34}$ which in turn enhance the transcriptional activity of STAT3 to upregulate Mcl-1 gene transcription. ${ }^{35}$ Other reported pathways that induce $\mathrm{Mcl}-1$ levels in myometrial cells are the NFkB pathway, endoplasmic reticulum stress response and its adaptive unfolded protein response. ${ }^{4}$ Through different mechanisms, these pathways add to the contribution of AR signaling to sustain high levels of Mcl-1 present in myometrial cells and to ensure an antiapoptotic environment through this phase of pregnancy.

Our studies suggest that the AR may interact with other steroid receptors to control myometrial cells in response to apoptosis. AR protein levels were relatively high in the proliferation phase and low during the late secretory phase of the menstrual cycle, implying that estradiol and progesterone regulate AR gene expression. ${ }^{36}$ Using ovariectomized mice, AR
mRNA levels were shown to be mildly upregulated by estradiol in the myometrium. ${ }^{37}$ However, no impressive increases of $A R$ protein levels were apparent. ${ }^{18,38}$ As these studies were performed using whole-uterine tissues, it is possible that this represents a paracrine action involving the endometrium, stroma and myometrium. In our myometrial cell model, microarray combined with real-time PCR assays did not show any AR regulation of $E R$ and $P R$ expression. These findings do not exclude the possibility that AR may alter ER or PR function by cross talk with IGF or EGF signal pathways, as the downstream effectors, Akt and Src kinase are important to transduce steroid hormone signaling. Akt and Src are thus attractive therapeutic targets to block myometrial cell proliferation and induce apoptotic cell death. Recent studies have shown that Akt inhibitors can reduce leiomyoma cell viability and leiomyoma tumor volume. ${ }^{39}$ It is of interest to test whether combining AKT blocker and AR antagonist (e.g. MDV3100) would result in synergistic suppression of leiomyoma tumor growth.

Though our results on the antiapoptotic actions of AR were collected from in vitro myometrial hTERT-HM cell model, further studies shall apply in vivo animal models (e.g. the female AR knockout mice). These animal models have the privilege to study the paracrine regulation of AR signaling by growth hormones and other sex steroids among myometrium, stroma and endometrium.

In summary, our studies demonstrated that the AR exerts antiapoptotic functions in human myometrial cells and the AR signaling is an important component of myometrium phenotype programming during pregnancy.

\section{Materials and Methods}

Tissue culture and western blotting. Paternal human myometrial cells were received from Dr. Condon (University of Pittsburgh) and referred to as hTERT-HM. As described in our previous study, ${ }^{18}$ hTERT-HM cells stably expressing control shRNA or shRNA against AR were designated as hTERT(shAR) and hTERT(shCTRL), whereas cells overexpressing mock or AR cDNA were designated as hTERT(AR), hTERT(Mock). When steroid hormone treatments were used, cells were first cultured in phenol red-free DMEM medium containing 5\% charcoal-stripped serum (Hyclone, Logan, UT, USA) for $48 \mathrm{~h}$. Protein was extracted in lysis buffer containing $50 \mathrm{mM}$ Tris (pH 8.0), $150 \mathrm{mM} \mathrm{NaCl}$, $1 \%$ Nonidet P-40, $0.5 \%$ sodium deoxycholate, $0.1 \%$ sodium dodecyl sulfate. Western blotting assays were performed using antibodies listed in the Supplementary Table. The density of protein bands was measured using Image $\mathrm{J}$ software analysis (NIH, Bethesda, MD, USA). The values of each sample were expressed as a ratio of protein of interest to the housekeeping protein. R1881, CPT, LY294002, WP1066, PP2 and EGF were purchased from Cedarlane (Burlington, ON, Canada). MDV3100 was from Haoyuan Chemexpress (Shanghai, China). MIM1 was from Tocris (Bristol, UK). Detailed information of antibodies and primers are listed in Supplementary Table.

UV light and anti-Fas antibody induced apoptosis. cells were serum starved for $12 \mathrm{~h}$ before exposured to UV light (UV Stratalinker 1800) for various doses. Cells were allowed to recover for the indicated periods of time. To induce apoptosis through the extrinsic pathway, cells were treated with anti-Fas antibody (clone $\mathrm{CH} 110$ ) at various doses and time points. ${ }^{20}$ Cells were harvested and the percentage of cells with Annexin $\mathrm{V}$ binding was determined by flow cytometry. ${ }^{20}$ Protein lysates was extracted for western blotting of c-PARP1 and c-CASP3.

Flow cytometry. Annexin V-PE/7-AAD Apoptosis Detection Kit (BD Pharmingen, San Diego, CA, USA) were used to detect apoptotic cell populations according to manufacturer's protocol. Briefly, the cells $\left(1 \times 10^{5}\right.$ cells) were suspended in $100 \mu \mathrm{l}$ binding buffer, and then treated with $5 \mu \mathrm{l}$ of Annexin V-PE (BD Pharmingen) and $5 \mu \mathrm{l}$ 7-AAD before analyzed on FACSCanto II flow 
cytometer and BD FACSDiva software v5.0.3 (Becton Dickinson, Franklin, NJ, USA). Ten thousand events are acquired for statistical analysis. Detection of apoptotic population was performed according to the manufacturer's instructions (https://www.bdbiosciences.com/external_files/pm/doc/tds/cell_bio/live/web_enabled /6900KK_559763.pdf).

Microarray and Real-time PCR. Gene microarray analyses were performed as described before. ${ }^{40}$ Briefly, Total RNA was extracted from hTERT(shAR) and hTERT(shCTRL) cells by the mirVana RNA Isolation Kit (Ambion, Austin, TX, USA) from three independently repeated experiments. The quality and quantity of RNA were assessed with an Agilent 2100 Bioanalyzer (Caliper Technologies Corp., CA, USA). Amplified and Alexa Fluor 3 labeled RNA samples from hTERT(shCTRL) and hTERT(shAR) cells were hybridized onto the Human Agilent $4 \times 44 \mathrm{k}$ (Agilent Technologies, Santa Clara, CA, USA), along with Alexa Fluor 5 labeled human reference RNA. Hybridization signals were analyzed following the manufacturer's instruction. Statistical Analysis of Microarray (SAM) program (http://www-stat.stanford.edu/tibs/SAM/) was used to analyze expression differences between RNA samples from hTERT(shAR) and hTERT(shCTRL) cells. Unpaired $t$-tests were calculated for all probes passing filters and controlled for multiple testing by estimation of $q$-values using the false discovery rate method. ${ }^{41}$ IPA software (Ingenuity Systems) was used to analyze AR-regulated gene groups and signaling pathways.

Real-time PCR assays. Total RNA was extracted using Purelink RNA mini kit (Invitrogen, Burlington, ON, Canada) according to the manufacturer's instructions. Two micrograms of total RNA was subjected to a random-primed reverse transcription using M-MLV reverse transcriptase (Invitrogen). Real-time qPCR was conducted in triplicates using Applied Biosystems $7900 \mathrm{HT}$ with $5 \mathrm{ng}$ of CDNA, $1 \mu \mathrm{M}$ of each primer pair and SYBR Green PCR master mix (Roche, Mississauga, ON, Canada). The sequences of primers were shown below. Relative mRNA levels were normalized to GAPDH.

Statistics. Results are expressed as the mean \pm S.E.M. To determine differences between two groups, student $t$-test was carried out using GraphPad Prism (version 4) with the level of significance set at $P<0.05$ as *,$P<0.01$ as ** and $P<0.001$ as ***.

\section{Conflict of Interest}

The authors declare no conflict of interest.

Acknowledgements. This work is supported by Canadian Institutes of Health Research Operating Grant (MOP-111148) to XSD and SL and by a Rising Star Award (RS2013-58) from Prostate Cancer Canada to XSD.

1. Lye SJ, Tsui P, Dong X, Mitchell J, Dorogin A, MacPhee D et al. Myometrial programming: a new concept underlying the regulation of myometrial function during pregnancy. In: Petraglia F, Strauss III JF, Gabbe SG, Weiss G (ed) Preterm birth-mechanisms, mediators, prevention and interventions. Informa UK Ltd: London, UK, 2007, pp 1-18.

2. Shynlova $O$, Tsui $P$, Jaffer $S$, Lye SJ. Integration of endocrine and mechanical signals in the regulation of myometrial functions during pregnancy and labour. Eur J Obstet Gynecol Reprod Biol 2009; 144: S2-10.

3. Shynlova O, Oldenhof A, Dorogin A, Xu Q, Mu J, Nashman N et al. Myometrial apoptosis: activation of the caspase cascade in the pregnant rat myometrium at midgestation. Biol Reprodn 2006; 74: 839-849.

4. Jeyasuria $P$, Subedi K, Suresh A, Condon JC. Elevated levels of uterine anti-apoptotic signaling may activate NFKB and potentially confer resistance to caspase 3-mediated apoptotic cell death during pregnancy in mice. Biol Reprod 2011; 85: 417-424.

5. Suresh A, Subedi K, Kyathanahalli C, Jeyasuria P, Condon JC. Uterine endoplasmic reticulum stress and its unfolded protein response may regulate caspase 3 activation in the pregnant mouse uterus. PLoS One 2013; 8: e75152.

6. Ishikawa H, Ishi K, Serna VA, Kakazu R, Bulun SE, Kurita T. Progesterone is essential for maintenance and growth of uterine leiomyoma. Endocrinology 2010; 151: 2433-2442.

7. Shimomura $Y$, Matsuo $H$, Samoto $T$, Maruo T. Up-regulation by progesterone of proliferating cell nuclear antigen and epidermal growth factor expression in human uterine leiomyoma. J Clin Endocrinol Metab 1998; 83: 2192-2198.

8. Burroughs KD, Fuchs-Young R, Davis B, Walker CL. Altered hormonal responsiveness of proliferation and apoptosis during myometrial maturation and the development of uterine leiomyomas in the rat. Biol Reprod 2000; 63: 1322-1330.
9. Yin XJ, Wang G, Khan-Dawood FS. Requirements of phosphatidylinositol-3 kinase and mammalian target of rapamycin for estrogen-induced proliferation in uterine leiomyomaand myometrium-derived cell lines. Am JObstet Gynecol 2007; 196: 176 e171-175.

10. Adesanya OO, Zhou J, Bondy CA. Sex steroid regulation of insulin-like growth factor system gene expression and proliferation in primate myometrium. J Clin Endocrinol Metab 1996; 81: 1967-1974.

11. Rossi MJ, Chegini N, Masterson BJ. Presence of epidermal growth factor, platelet-derived growth factor, and their receptors in human myometrial tissue and smooth muscle cells: their action in smooth muscle cells in vitro. Endocrinology 1992; 130: 1716-1727.

12. Matsuo H, Kurachi O, Shimomura $Y$, Samoto T, Maruo T. Molecular bases for the actions of ovarian sex steroids in the regulation of proliferation and apoptosis of human uterine leiomyoma. Oncology 1999; 57: 49-58.

13. Yu L, Saile K, Swartz CD, He H, Zheng X, Kissling GE et al. Differential expression of receptor tyrosine kinases (RTKs) and IGF-I pathway activation in human uterine leiomyomas. Mol Med 2008; 14: 264-275.

14. Datta SR, Dudek H, Tao X, Masters S, Fu H, Gotoh $Y$ et al. Akt phosphorylation of BAD couples survival signals to the cell-intrinsic death machinery. Cell 1997; 91: 231-241.

15. Migliaccio A, Castoria G, Di Domenico M, de Falco A, Bilancio A, Lombardi M et al. Steroid-induced androgen receptor-oestradiol receptor beta-Src complex triggers prostate cancer cell proliferation. EMBO Jl 2000; 19: 5406-5417.

16. Migliaccio A, Di Domenico M, Castoria G, de Falco A, Bontempo P, Nola E et al. Tyrosine kinase/p21ras/MAP-kinase pathway activation by estradiol-receptor complex in MCF-7 cells. EMBO J 1996; 15: 1292-1300.

17. Castracane VD, Stewart DR, Gimpel T, Overstreet JW, Lasley BL. Maternal serum androgens in human pregnancy: early increases within the cycle of conception. Hum Reprod 1998; 13: 460-464.

18. Liu L, Li Y, Xie N, Shynlova O, Challis JR, Slater D et al. Proliferative action of the androgen receptor in human uterine myometrial cells-a key regulator for myometrium phenotype programming. J Clin Endocrinol Metab 2013; 98: 218-227.

19. Walters KA, Allan CM, Jimenez M, Lim PR, Davey RA, Zajac JD et al. Female mice haploinsufficient for an inactivated androgen receptor (AR) exhibit age-dependent defects that resemble the AR null phenotype of dysfunctional late follicle development, ovulation, and fertility. Endocrinology 2007; 148: 3674-3684.

20. Hayashi N, Peacock JW, Beraldi E, Zoubeidi A, Gleave ME, Ong CJ. Hsp27 silencing coordinately inhibits proliferation and promotes Fas-induced apoptosis by regulating the PEA-15 molecular switch. Cell Death Differ 2012; 19: 990-1002.

21. Feldman BJ, Feldman D. The development of androgen-independent prostate cancer. Nat Rev Cancer 2001; 1: 34-45.

22. Kitagawa D, Tanemura S, Ohata S, Shimizu N, Seo J, Nishitai G et al. Activation of extracellular signal-regulated kinase by ultraviolet is mediated through Src-dependent epidermal growth factor receptor phosphorylation. Its implication in an anti-apoptotic function. J Biol chemistry 2002; 277: 366-371.

23. Cohen NA, Stewart ML, Gavathiotis E, Tepper JL, Bruekner SR, Koss B et al. A competitive stapled peptide screen identifies a selective small molecule that overcomes MCL-1dependent leukemia cell survival. Chem Biol 2012; 19: 1175-1186.

24. Jaffer $S$, Shynlova $O$, Lye $S$. Mammalian target of rapamycin is activated in association with myometrial proliferation during pregnancy. Endocrinology 2009; 150: 4672-4680.

25. Igney $\mathrm{FH}, \mathrm{Krammer} \mathrm{PH}$. Death and anti-death: tumour resistance to apoptosis. Nat Rev Cancer 2002; 2: 277-288.

26. van Delft MF, Wei AH, Mason KD, Vandenberg CJ, Chen L, Czabotar PE et al. The BH3 mimetic ABT-737 targets selective Bcl-2 proteins and efficiently induces apoptosis via Bak/Bax if Mcl-1 is neutralized. Cancer Cell 2006; 10: 389-399.

27. Scaffidi C, Fulda S, Srinivasan A, Friesen C, Li F, Tomaselli KJ et al. Two CD95 (APO-1/Fas) signaling pathways. EMBO J 1998; 17: 1675-1687.

28. Jeyasuria $P$, Wetzel J, Bradley M, Subedi K, Condon JC. Progesterone-regulated caspase 3 action in the mouse may play a role in uterine quiescence during pregnancy through fragmentation of uterine myocyte contractile proteins. Biol Reprod 2009; 80: 928-934.

29. Liu H, Perlman H, Pagliari LJ, Pope RM. Constitutively activated Akt-1 is vital for the survival of human monocyte-differentiated macrophages. Role of $\mathrm{Mcl}-1$, independent of nuclear factor (NF)-kappaB, Bad, or caspase activation. J Exp Med 2001; 194: 113-126.

30. Mills JR, Hippo Y, Robert F, Chen SM, Malina A, Lin CJ et al. mTORC1 promotes survival through translational control of Mcl-1. Proc Natl Acad Sci USA 2008; 105: 10853-10858.

31. Coloff JL, Macintyre AN, Nichols AG, Liu T, Gallo CA, Plas DR et al. Akt-dependent glucose metabolism promotes Mcl-1 synthesis to maintain cell survival and resistance to Bcl-2 inhibition. Cancer Res 2011; 71: 5204-5213.

32. Maurer U, Charvet C, Wagman AS, Dejardin E, Green DR. Glycogen synthase kinase-3 regulates mitochondrial outer membrane permeabilization and apoptosis by destabilization of MCL-1. Mol Cell 2006; 21: 749-760.

33. Wang JM, Chao JR, Chen W, Kuo ML, Yen JJ, Yang-Yen HF. The antiapoptotic gene mcl-1 is up-regulated by the phosphatidylinositol 3-kinase/Akt signaling pathway through a transcription factor complex containing CREB. Mol Cell Biol 1999; 19: 6195-6206.

34. Castoria G, Lombardi M, Barone MV, Bilancio A, Di Domenico M, Bottero D et al. Androgen-stimulated DNA synthesis and cytoskeletal changes in fibroblasts by a nontranscriptional receptor action. J Cell Biol 2003; 161: 547-556. 
35. Epling-Burnette PK, Liu JH, Catlett-Falcone R, Turkson J, Oshiro M, Kothapalli R et al. Inhibition of STAT3 signaling leads to apoptosis of leukemic large granular lymphocytes and decreased Mcl-1 expression. J Clin Invest 2001; 107: 351-362.

36. Mertens HJ, Heineman MJ, Theunissen PH, de Jong FH, Evers JL. Androgen, estrogen and progesterone receptor expression in the human uterus during the menstrual cycle. Eur J Obstet Gynecol Reprod Biol 2001; 98: 58-65.

37. Pelletier G, Luu-The V, Li S, Labrie F. Localization and estrogenic regulation of androgen receptor mRNA expression in the mouse uterus and vagina. J Endocrinol 2004; 180: 77-85.

38. Weihua Z, Ekman J, Almkvist A, Saji S, Wang L, Warner M et al. Involvement of androgen receptor in 17beta-estradiol-induced cell proliferation in rat uterus. Biol Reprod 2002; 67: 616-623.

39. Sefton EC, Qiang W, Serna V, Kurita T, Wei JJ, Chakravarti D et al. MK-2206, an AKT inhibitor, promotes caspase-independent cell death and inhibits leiomyoma growth Endocrinology 2013; 154: 4046-4057.

40. Yu Y, Liu L, Xie N, Xue H, Fazli L, Buttyan R et al. Expression and function of the progesterone receptor in human prostate stroma provide novel insights to cell proliferation control. J Clin Endocrinol Metab 2013; 98: 2887-2896.
41. Larson SR, Zhang X, Dumpit R, Coleman I, Lakely B, Roudier M et al. Characterization of osteoblastic and osteolytic proteins in prostate cancer bone metastases. Prostate 2013; 73: 932-940.

cc)(i)(2)(2) Cell Death and Disease is an open-access journal published by Nature Publishing Group. This work is licensed under a Creative Commons Attribution-NonCommercialShareAlike 3.0 Unported License. The images or other third party material in this article are included in the article's Creative Commons license, unless indicated otherwise in the credit line; if the material is not included under the Creative Commons license, users will need to obtain permission from the license holder to reproduce the material. To view a copy of this license, visit http://creativecommons.org/ licenses/by-nc-sa/3.0/

Supplementary Information accompanies this paper on Cell Death and Disease website (http://www.nature.com/cddis) 